\title{
The Implementation of Smart Grid to the Simulating Toolkit Modes
}

\author{
Jozef Dudiak $^{1 *}$, Michal Kolcun ${ }^{2}$, Zsolt Čonka ${ }^{3}$, Michal Kolcun, Jr. ${ }^{4}$ \\ ${ }^{1-4}$ Technical University of Košice
}

\begin{abstract}
This paper discusses the implementation of the renewable energy sources and the energy storage system to the smart grid by means of simulating toolkit of Modes. The output curve of photovoltaic and wind power plant is also the part of this paper. This paper analyses the difference between residential and commercial load. The test system was made in Modes for modelling all possibilities. The possibility of connection energy storage is analysed. The storage system is used for charming the load peaks during the day to compare smart grids with energy storage and without it.
\end{abstract}

Keywords - Daily load diagram, energy storage, island operation, Modes, power system stability, smart grid.

\section{INTRODUCTION}

Smart grids combine the traditional techniques with innovative digital solutions, thereby increasing the flexibility of managing the power supply through efficient exchange of information. One recent application of intelligent networks is the integration of individual operations of electricity produced from renewable sources that follows the expansion of the environment objectives set by the European Commission. In this continuously evolving system, the customer becomes an active participant in the energy system with transparent energy flows entering the energy market and using it effectively. Smart grids increase the quality of service. Operating costs are decreasing, and competitiveness of network operators is growing. These are benefits for environmental sustainability and for the whole system. Energy distribution networks are changing. In the near future, electric network will enable an efficient exchange of energy from sources with minimal greenhouse gas emissions. The development of electro mobility and conversion of entire cities into new and more modern district with low impact on the environment are increased. [1][3].

Smart grids use a two-way transmission of electricity and information to create advanced automated network for power supply. The use of advanced information technology, intelligent network capable of transmitting electrical power with greater efficiency and able to respond to the wide range of operating conditions and contingencies. Intelligent networks can respond to events that occur anywhere on the network, such as production, transmission, distribution and consumption of electricity, and take adequate response. For example, if there is a failure of the transformer in the distribution network, intelligent network automatically changes the energy flow and restores the operation of the transmission network. Transaction information is collected by means of intelligent networks and their subsystems, which then allows the operator to quickly identify the best solution to secure networks against attack and vulnerability caused by different eventualities [4]-[6].

Smart grids can be considered as an electricity system that uses two-way cyber secure transmission of information and computational tools in an integrated form of the entire electrical network. This results in a system that is clean, safe, reliable and flexible working with high efficiency. Two-way transmission in smart grids means that consumers do not only consume energy but also supply energy to the network. For example, generating the electricity by using photovoltaic panels and turning it into supply to the network. Thanks to real-time measurements, users can actively participate in the operation of the system [7].

\section{Modeling THE POWER SySTEM WITH A SMART GRID}

For modelling purposes of the smart grid, we had used the simulation toolkit of Modes. A power system at a medium and low voltage level was modelled. To that power system, we started to implement smart grids with all features offered by this intelligent power system.

The smart grid is divided into two voltage levels as well. The voltage level $22 \mathrm{kV}$ is considered the backbone of the grid, and there are conventional power energy sources, such as biogas, hydropower plant, and also wind. Main load at this level is divided into intelligent buildings and other commercial parks. So the daily load diagram is also divided according to the average consumption for the commercial and residential load diagram. 


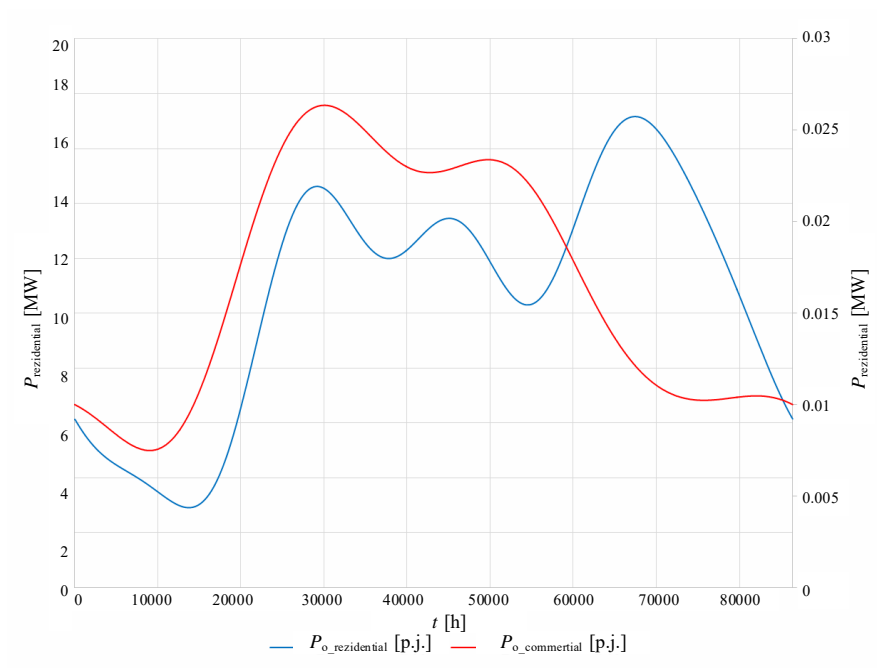

Fig. 1. Output of daily load diagram for a modelled power system.

The program "Modes" has several parameters for setting blocks of the daily load diagram. We always use the whole day for modelling the smart grids. Fig. 1 shows the curve of the daily load diagram for a modelled power system. It can be seen that the commercial load diagram has one peak during the day, when many people are at work and the building needs to be supplied. Otherwise the residential load has two peaks. The first one is in the morning, when population is getting up, and the other is in the evening, when people are watching television with the lights turned on.

The pervious graph is very useful for designing smart power energy sources for the smart grid. According to the load, we must design supplement of power to ensure the power stability in every moment. For this purpose, we had used the model of photovoltaic power plant and also the model of wind power plant. The whole smart grid is regulated by the energy storage system to eliminate the peaks of load during the day. The cooperation of these power sources is important for maintaining the stability of frequency and voltage.

Fig. 2 shows that the energy storage system uses the storage energy for reduction of the peak of load diagram (marked in red). The battery is charging during the night and day when the load is under the limit for regulation. The aim of using the energy storage system is smoothing the load and making it more effective. This energy can be used in standby mode for eventual blackout or just for regulation of the active power. Also, Fig. 2 displays the power supplied from a wind power plant that is regulated for constant power; in case of strong gusts of wind, the supplied power is increased. The most unpredictable is photovoltaic power plant. Besides, Fig. 2 shows the output of active power during sunny days so this state isn't very difficult for regulation. A different situation appears when the sky is cloudy and supplied power has an oscillating character.

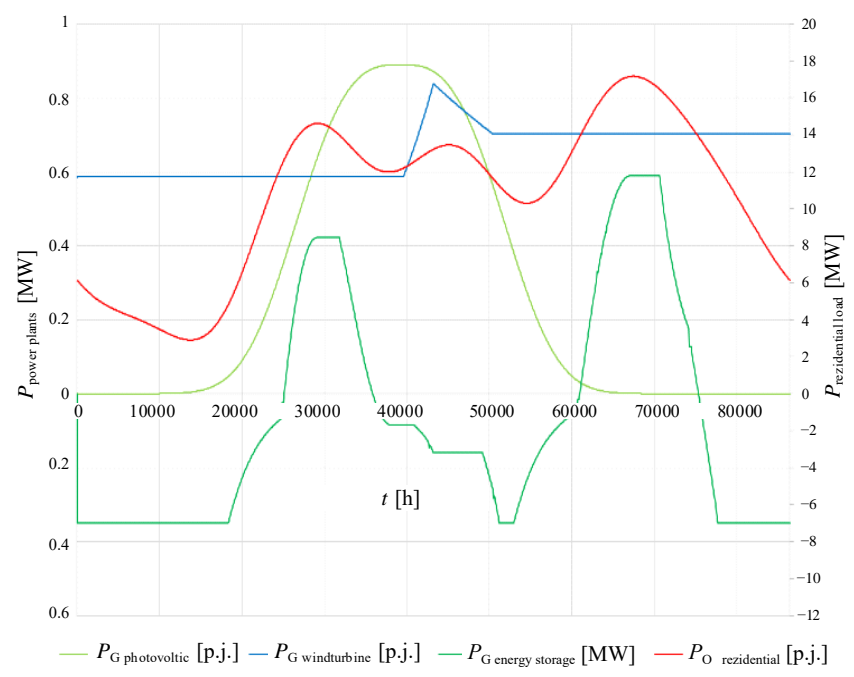

Fig. 2. Cooperation of photovoltaic, wind and energy storage with load in the smart grid.

Reconciliation of all this renewables and energy storage systems together with load in the grid is a challenge for all technicians. We also know some smart grids that are selfsufficient and can operate in the island mode as well. But all of them are only at the level of a demonstration project, lacking a proper legislation and financial background in order to implement these new technologies in practice.

\section{MANAGEMENT OF ENERGy StORAGE SySTEMS}

The stability of the system and the steady state maintenance influence many factors, in particular operating parameters. The energy storage system (ESS) belongs to the core elements of the smart grid. By combining these systems and renewable energy sources, we can ensure the stabilization and storage of excessive energy during production in peaks and then use that energy in case of increased load. By the ESS we have two modes of storage. The control of frequency and integration of large amount of renewable energy sources so the need for high power to cover the energy demand, it is microgrid application for connection to the main grid. In the island operation mode, the main task of ESS is improving the system quality, ensuring the grid stability, and quick response for transient phenomena [8], [10], [11].

Energy storage systems can be used as centralized or decentralized. The centralized systems operate according to the same principle as the central controller, and regulation of the microgrid is controlled by the central system in which, if necessary, the entire capacity of the storage is used. From the perspective of the central storage, these can be connected to the DC voltage node or in combination with power electronic components to the AC voltage node. This model of centralized energy storage is typical for the microgrid with a small overall load and a low number of sources. The decentralized configuration of ESS is an accumulation system connected directly to each source through various electronic interfaces. With this configuration, each storage system is responsible for managing and optimizing the output power from the sources with which it is connected [9]. 
In the microgrid, control of the active power provided by ESS needs to be monitored continuously in cooperation with the primary control. The ability of the grid to respond to the changes in the active power is based on monitoring the changes in frequency. If the system frequency is increasing, it means that the produced active power is greater than the consumption at the time and thus it is necessary to absorb the energy in ESS when it allows the current state of charge. When the load is increasing, there is a lack of active power in the grid and thus the system frequency decreases. If the value of the system frequency is close to the minimum, it needs to be injected power from ESS to maintain the stability and required quality. The control of the microgrid with ESS by means of reactive power is not optimal. It is more appropriate to set the value of reactive power on the charging device to zero, and thus charging and discharging will start in the absence, respectively surplus, of active power in the grid. Secondary control in the charging system ensures that the output power fell to zero and control of the charging and discharging according to the requirements of primary regulation. This management is done by comparing the output power from the ESS and the reference value of active power. The result of this comparison is the value that controls the charging process [10], [11].

\section{THE OUTPUT OF LOAD AND ESS COOPERATION}

The cooperation of ESS and load was made by means of Modes. Fig. 3 displays the output active power from ESS. The areas where this system is charging and the time when the energy is used for supplement to the grid can be seen. The whole operation of ESS is regulated by the availability of the active power in the grid, so it influences the load at the minimum rate. Fig. 3 also shows the state of charge curve. This state is important for secondary regulation of the power system. It tells how much energy in the system is available for the regulation. This is important for maintaining the power stability because the system is charging according that curve. We can effectively manage the daily production when we know values of battery state of charge curve. And finally we have there the power flow in the regulation line in comparison with ESS and without them. We can see the effectivity of usage the energy storage systems. There are chamfered peaks during the day. The ESS in program Modes works on the principle of regulation the active power in the power line. When the value of the active power flow is increased over the set value, it causes the supply of the power from ESS. When the value is lower than the set value it means that ESS is charging the energy and increase the load. The first peak was chamfered when using $70 \%$ of the capacity of ESS. The second peak was chamfered when using $90 \%$ of the capacity of ESS, which is the limit of its usage. This ESS was designed for chamfering all peaks during the day.

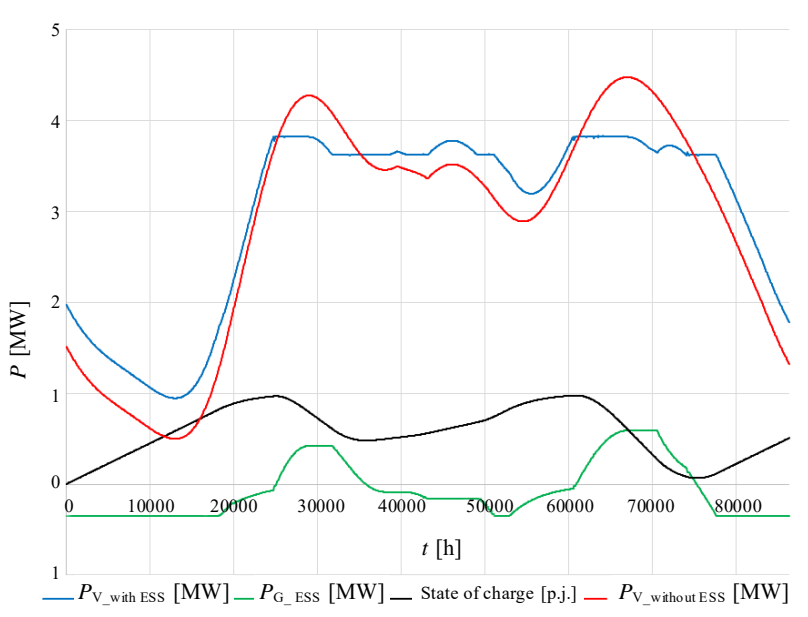

Fig. 3. Output of the Energy storage system.

Fig. 4 shows the final curve of energy power flow, using ESS. As mentioned in the previous chapter, the principle is based on the power flow over the line in the regulation area. It regulates the total active power in one area of regulation. The battery in ESS is charging with active power from $0 \mathrm{MW}$ to $0.7 \mathrm{MW}$. The average value of charging is $0.2 \mathrm{MW}$, which means that the prevalent time of the day is when the consumption of ESS is of about $0.2 \mathrm{MW}$. The maximum power that can be used from the battery is nominal minus $10 \%$. So we have used all of the power from battery for shaving peaks and after that the battery is charged during the night or off peak periods. Moreover, the smart grid power balance can be maintained by charging or discharging the energy storage as needed. The ESS control capability of balancing between generation and consumption may be restricted by the available system capacity. The hierarchical control of the smart grid can be divided into three sections, as the big interconnected power systems.

Primary control ensures the regulation of frequency and voltage deviation from the reference values. The deviation arises from the internal control fool of voltage and frequency. Primary regulation ensures the fastest response to every change within production and consumption and increases the system's stability.

Secondary control ensures that the electrical metering values are within the reference limits. This level provides also the synchronization control loop for seamless connection of the smart grid to the main grid, and also its disconnection if necessary.

Tertiary control ensures the regulation of power flow between the microgrid and the main grid. 


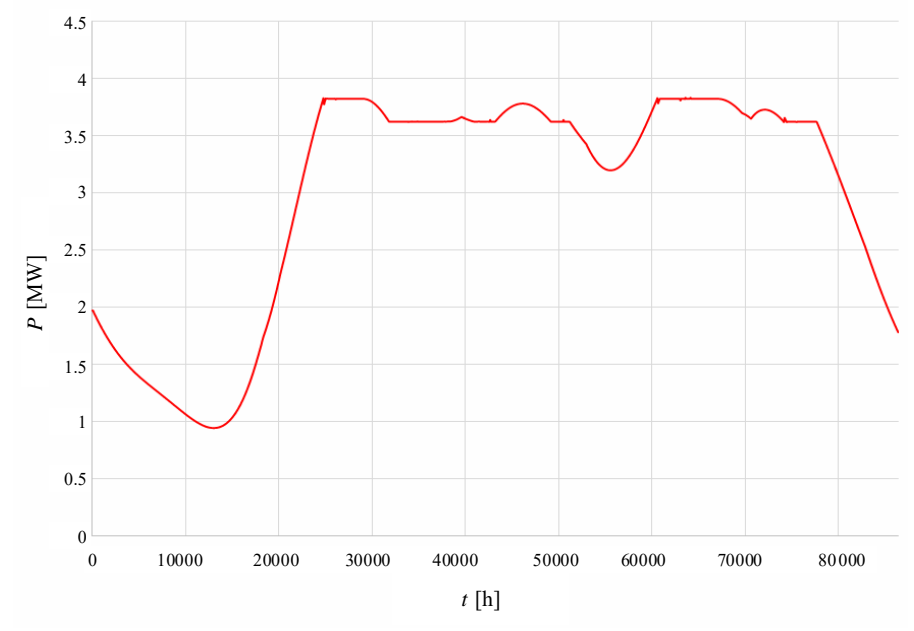

Fig. 4. Final curve of energy power flow regulated by ESS.

\section{CONCLUSION}

The aim of modelling the smart grid with ESS in the program "Modes" was to analyze the impact of its operation within the smart grid. The model of ESS was invented and described by the author of the program. The whole analyzation of implementation renewables and ESS to the grid needs a complex view on the new way of the power energy sector. There are some results from hypothesis and simulations of smart grid. The simulation study also demonstrates power generation from renewable energy sources that are used for coverage of the load during the day. Our analyses suggest that it is possible to implement ESS to the grid and use it for chamfering the load peaks by charging and discharging the ESS. The aim of ESS is to ensure the load curve as smooth as possible. The present paper also highlights the importance of monitoring the state-of-charge for ESS. This state is the basis of maintaining the active power in the smart grid and in the island mode operation when there is no possibility of connecting the smart grid to the main grid.

\section{ACKNOWLEDGMENT}

This work was supported by the Slovak Research Agency No. VEGA 2/0071/16 project.

\section{REFERENCES}

[1] J. M. Guerrero et al., "Hierarchical control of droop-controlled AC and DC microgrids - a general approach toward standardization," IEEE Trans. Ind. Electron., vol. 58, 2011, pp. 158-172. http://dx.doi.org/10.1109/TIE.2010.2066534

[2] A. Bidram and A. Davoudi, "Hierarchical structure of microgrids control system," IEEE Trans. Smart Grid, 2012, pp. 1963-1976. http://dx.doi.org/10.1109/tsg.2012.2197425

[3] B. Kroposki, et al., "Microgrid standards and technologies," in Power and energy society general meeting-conversion and delivery of electrical energy in the 21st Century, IEEE, 2008, pp. 1-4. http://dx.doi.org/10.1109/PES.2008.4596703

[4] EREC. "Mapping Renewable Energy Pathways towards 2020 EU RoadMap," [Online]. Available: http://www.repap2020.eu/fileadmin/ user upload/Roadmaps/EREC-roadmap-V4 final.pdf

[5] S. Borlase, Smart Grid, Infrastructure, Technology and Solutions, Boca Raton: CRC Press, 2013. p. 577. ISBN 978-1-4398-2905-9.

[6] Q. Shaffie et al., "Distributed Secondary Control for Islanded Microgrids A Novel Approach," IEEE Trans. on Power Electron., vol. 29, no. 2, Feb. 2014, pp. 1018-1031. http://dx.doi.org/10.1109/TPEL.2013.2259506
[7] M. Kolcun, et al., Prevádzka elektrizačnej sústavy, Košice, Slovakia: TUKE, 2007, pp. 306.

[8] J. Dudiak, "Modelovanie podporných služieb v programe MODES," Diploma thesis. Košice, Slovakia, 2013.

[9] J. Hocko, "Výskum vplyvu obnovitel'ných zdrojov energie na podporné služby v elektrizačných sústavách," Dissertation thesis, Košice, Slovakia, 2013.

[10] J. Dudiak, et al., "Analyse of influence of renewable energy sources to the power system," Elektroenergetika 2013, Stará Lesná, Slovak Republic, 2013.

[11] P. Hocko, et al., "Analyse of influence of PVs on island operation in power system,” Elektroenergetika 2013, Stará Lesná, Slovak Republic, 2013.

[12] EWIS report "EWIS - Model sústavy," [Online]. Available: http://www.wind-integration.eu, Accessed on: March 1, 2014.

[13] ENTSO-E "Operational handbook," [Online]. Available: https://www.entsoe.eu/resources/consultations/closedconsultations/operation-handbook, Accessed on: March 2, 2014

[14] K. Vikash, et al., "Frequency Control of smart Grid A MATLAB/SIMULINK Approach," Int. J. of Eng. Research \& Technology, vol. 2, no. 10, 2013. ISSN 2278-0181. 